\title{
Fracture resistance and failure mode of layered translucent zirconia with different crown designs
}

\author{
Saif H. AL-QAYSI ${ }^{1}$, Abdul Rahman MOHAMMED SALEH ${ }^{1}$ and Hatem M. EL-DAMANHOURY² \\ ${ }^{1}$ Department of Clinical Sciences, College of Dentistry, Ajman University, Ajman, UAE \\ ${ }^{2}$ Department of Preventive and Restorative Dentistry, College of Dental Medicine, University of Sharjah, Sharjah, UAE \\ Corresponding author, Abdul Rahman MOHAMMED SALEH; E-mail: rm.saleh@ajman.ac.ae
}

\begin{abstract}
This study investigated the impact of different veneering design on the fracture resistance and failure mode of layered translucent zirconia crowns, compared to the full monolithic zirconia crowns. Ninety crowns with different designs were divided into six groups $(n=15)$; one fully contoured monolithic crown (FMC), one fully veneered with porcelain (FVC), or four partially veneered designs. All crowns were thermo-cycled, and then loaded to failure in a universal testing machine. The fracture resistance $(\mathrm{N})$ and fracture modes were assessed. One-way ANOVA was performed followed by Tukey's multiple comparison $(\alpha<0.05)$. Results demonstrated that all the tested partially veneered designs exhibited enhanced fracture resistances and were comparable to that of the full-contour monolithic translucent zirconia crowns.
\end{abstract}

Keywords: Translucent zirconia, Partially veneered zirconia, Fully veneered zirconia, Monolithic zirconia

\section{INTRODUCTION}

All-ceramic crowns and fixed partial dentures became the standard choice for most dentists in the last two decades, with a dramatic decline in the demand for metal-ceramic restorations ${ }^{1,2)}$. The improved esthetic properties of allceramic restorations are mainly attributed to enhanced optical properties, especially the improved translucency that made it possible to match and replicate the natural tooth characteristics ${ }^{3,4)}$.

A wide range of ceramic materials has been developed to meet the esthetic demand. However, the mechanical properties of glass-based ceramics, such as fracture toughness, low tensile strength, and wear resistance, have limited their clinical use $\mathrm{e}^{5}$. The introduction of zirconia-supported ceramic has generated considerable interest in restorative dentistry because of its high esthetics, biocompatibility, chemical, and mechanical durability ${ }^{6}$.

One main drawback of zirconia-based ceramics is their high opacity, which limited their use in the esthetic zone. Porcelain veneering of a zirconia core material has resulted in more esthetically accepted restorations ${ }^{7-9)}$. However, the chipping of veneered porcelain is the primary clinical weakness of dental bilayered ceramic structures, with a rate of $(6 \%$ and $15 \%)$ over 3 to 5 years ${ }^{10-13)}$. Other failures are often multifactorial and can be associated with improper thermal-related interfacial residual stresses, substructural design, and nonstandardized processing techniques ${ }^{14)}$. The main triggers for unsuitable residual stresses during fabricating the bilayered ceramic restorations are the different ceramic cooling rate, resulting from the mismatch in coefficients of thermal expansion of zirconia core and the veneering

Color figures can be viewed in the online issue, which is available at J-STAGE.

Received Feb 8, 2021: Accepted Jun 23, 2021

doi:10.4012/dmj.2021-051 JOI JST.JSTAGE/dmj/2021-051 porcelain ${ }^{15-17)}$. This opened the door for the introduction of the full contoured zirconia restoration (monolithic zirconia), which is manufactured by the CAD/CAM technology.

The main advantage of the monolithic zirconia is the elimination of porcelain chipping from the bilayered restorations ${ }^{18-20)}$. However, this material's main shortcoming was the esthetic performance due to the lack of achieving natural transparency ${ }^{18,21)}$. Several studies attempted to improve the opaque zirconia's esthetic appearance by introducing the full contour translucent zirconia, which was claimed that the material is combining the translucent esthetic properties with sufficient fracture resistance ${ }^{22)}$.

Several advantages made the translucent zirconia the material of choice over the other dental restorations; its relative translucency has been considered one of the main advantages, which categorized it as an esthetic material that indicates its use for anterior fixed prostheses ${ }^{23)}$. Other advantages include the mechanical strength, where the studies showed that the fracture strength of the translucent zirconia is greater than that of lithium disilicate and multilayered restoration ${ }^{24-26)}$, however, the strength of translucent zirconia is brand dependent ${ }^{27}$. The tooth preparation for monolithic crowns is relatively minimal and saves more tooth structures compared to other ceramic materials. Nakamura et al. indicated that translucent zirconia in $0.5 \mathrm{~mm}$ thickness had a higher fracture strength compared to lithium disilicate with 1.5 mm occlusal thickness ${ }^{28)}$.

However, there are two main drawbacks of the translucent zirconia, the first one is its susceptibility to low-temperature degradation (LTD), in which the spontaneous phase transformation from tetragonal to monoclinic is higher compared to traditional veneered zirconia. The veneering porcelain in the multilayered 
zirconia restorations protects the zirconia core from direct exposure to the oral environment and reduce such degradation. The absence of the veneering porcelain in the translucent zirconia crowns makes it more susceptible to $\mathrm{LTD}^{29-31)}$. The second drawback of translucent zirconia is its suboptimal esthetic properties; the translucent zirconia is still less translucent than lithium disilicate according to the translucency parameter (TP). The $\mathrm{TP}$ is defined as the color difference of a material of a given thickness over white and black backgrounds ${ }^{32}$. Yu et al. in 2009 reported that the TP values of $1 \mathrm{~mm}$ thickness of human dentin and enamel is 16.4 and 18.7, respectively ${ }^{33)}$. The $\mathrm{TP}$ of translucent zirconia is ranging between 11.2 and 15.3 , which is significantly less translucent compared to enamel and to lithium disilicate, which have a TP value of $16.89^{26)}$.

The effect of porcelain veneering of translucent zirconia crowns' mechanical behavior has not been investigated in the literature previously. Therefore, this study aimed to assess the effect of different crown designs on the fracture resistance of thermally-fatigued veneered translucent zirconia crowns compared to the full-contoured monolithic translucent zirconia crowns.

\section{MATERIALS AND METHODS}

\section{Dies preparation}

Hard thermo-setting plastic tooth models of tooth \#46 (Frasaco, Tettnang, Germany) was scanned using a 3D scanner (Ceramill map 400+, Amann Girrbach, Koblach, Austria). Then prepared with 10-20 degree total occlusal convergence, $1.0 \mathrm{~mm}$ uniform reduction of the buccal, lingual, and occlusal surfaces, and the proximal surfaces were prepared to remove the undercuts with a minimum reduction of $1.0 \mathrm{~mm}$ with round-end tapered diamond bur (8868.314.012/868.314.012 burs; Komet Dental, Lemgo, Germany). The plastic tooth was duplicated using a polyurethane-based model stump material (alpha die MF ivory precision die material, Schütz Dental, Rosbach, Germany) to a ninety duplicated dies.

\section{Crown fabrication}

A total of 90 standardized crowns with different designs were fabricated and divided into six groups $(n=15)$; The tested crown designs are illustrated in Fig. 1.

Group 1: $1 \mathrm{~mm}$-thick fully contoured monolithic translucent zirconia crown (FMC).

Group 2: Fully veneered translucent zirconia core with $0.5 \mathrm{~mm}$ porcelain veneer (FVC).

Group 3: Partially veneered translucent zirconia crown with a $0.5 \mathrm{~mm}$ buccal veneer (PVL).

Group 4: Partially veneered translucent zirconia crown with a $0.5 \mathrm{~mm}$ buccal veneer with 1 $\mathrm{mm}$ buccal collar height (PVCo).

Group 5: Partially veneered translucent zirconia crown with $0.5 \mathrm{~mm}$ buccal veneer supported by wave design (PVW).

Group 6: Partially veneered translucent zirconia crown with $0.5 \mathrm{~mm}$ buccal veneer supported by occlusal cap design (PVCa).
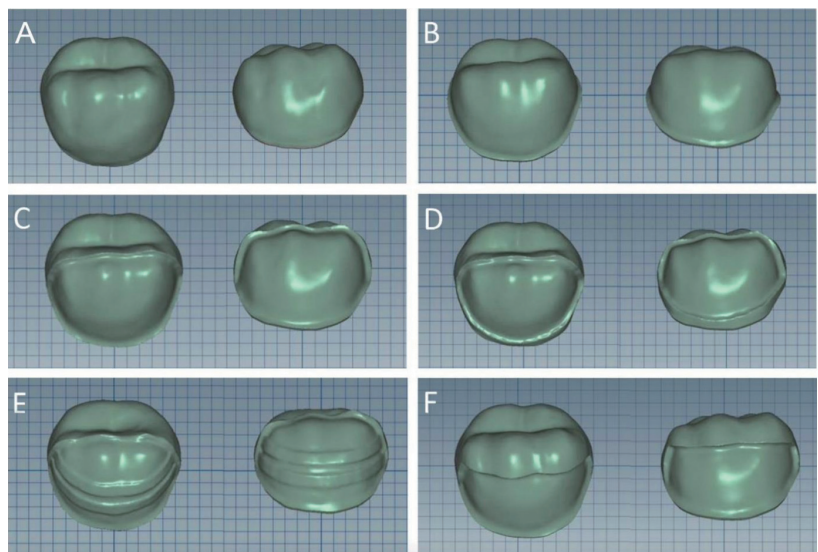

Fig. 1 A 3D illustration of the experimental crown design groups.

A) group 1: fully contoured monolithic translucent zirconia crown design; B) group 2: fully veneered translucent zirconia core with $0.5 \mathrm{~mm}$ porcelain veneer design; C) group 3: partially veneered translucent zirconia crown with $0.5 \mathrm{~mm}$ buccal veneer design; D) group 4: partially veneered translucent zirconia crown with $0.5 \mathrm{~mm}$ buccal veneer with $1 \mathrm{~mm}$ buccal collar height design; E) group 5: partially veneered translucent zirconia crown with $0.5 \mathrm{~mm}$ buccal veneer supported by wave design; F) group 6: partially veneered translucent zirconia crown with $0.5 \mathrm{~mm}$ buccal veneer supported by occlusal cap design

The designing of the respective crowns was performed using CAD software (Ceramill Mind software, Amann Girrbach) according to our study design. All the crowns were milled from pre-shaded translucent zirconia blocks (Ceramil, Zolid HT+ pre-shaded, Amann Girrbach), using a 5-axis milling machine (Ceramill Motion 2, Amann Girrbach). The milled crowns were sintered at $1,450^{\circ} \mathrm{C}$ for $9.5 \mathrm{~h}$ using a sintering furnace (Ceramill therm 3, Amann Girrbach).

The veneering surface of the crown copings with reduced anatomical shape (Groups 2-6) were sandblasted with $50 \mu$ aluminum oxide particles (Korox50-Crndm-Blast-Mat, Bremen, Germany) under a pressure of 30 psi for $15 \mathrm{~s}$ at a direction perpendicular to the veneering surface, and steam cleaned for $5 \mathrm{~s}$ before applying the porcelain veneer layer. Feldspathic porcelain (Soprano 10, Cendres+Métaux Medtech, Biel/ Bienne, Switzerland) was applied in multiple layers (Modifier, Dentin A2, Enamel A2, glaze), and the crowns were fired in a calibrated furnace according to the manufacture recommendation. The crown's thickness was measured at five standardized points, using a dial gauge (Calipretto CR, Renfert, Hilzingen, Germany) to verify the thickness.

\section{Cementation}

The surface of the dies were sandblasted with $50 \mu \mathrm{m}$ aluminium oxide particles and cleaned in an ultrasonic 
water bath. Each crown was bonded onto its respective die using a self-adhesive resin cement (RelyX Unicem 2 Automix, 3M ESPE, Seefeld, Germany). A standardized static load $(20 \mathrm{~N})$ was applied on the occlusal surface of each crown for $30 \mathrm{~s}$, and then the excess cement was removed from the margins using a micro-brush. All the specimens were light-cured for $20 \mathrm{~s}$ from the buccal and lingual aspects using an LED light-curing unit (Elipar DeepCure, 3M ESPE) with an output of $1,470 \mathrm{~mW} / \mathrm{cm}^{2}$. The intensity was verified in every 10 samples using a digital radiometer (Cure Rite, Dentsply, Milford, DE, USA) to ensure uniform curing. Specimens were stored in a moist environment for $24 \mathrm{~h}$ at $37^{\circ} \mathrm{C}$ in an incubator before the mechanical testing (Incubator I, Memmert, Schwabach, Germany).

\section{Thermal aging}

The specimens were simultaneously thermo-cycled for 5,000 cycles between two temperature extremes of $5^{\circ} \mathrm{C}$ and $55^{\circ} \mathrm{C}$ in distilled water (dwell time: $30 \mathrm{~s}$, pause time: $13 \mathrm{~s}$ ) and performed in a computerized thermocycling unit (SD Mechatronik, Feldkirchen Westerham, Germany).

\section{Fracture resistance testing}

All specimens were loaded to fracture in a universal testing machine (Universal testing machine, M3505CT, Testometric, Rochdale, UK). A custom-made semispherical stainless-steel indenter $(\varnothing=4 \mathrm{~mm})$ was used, and each sample was positioned at a $45^{\circ}$ to the indenter's long axis. The indenter was placed against the lingual inclination of the buccal cusp on a standardized occlusal point $2 \mathrm{~mm}$ away from the cusp tip. A compressive load was applied vertically at a crosshead speed of $1.0 \mathrm{~mm} /$ min until fracture. The load at failure was recorded in Newtons (N).

\section{Failure mode analysis}

The fractured surfaces of the crowns were assessed by two examiners. A gross visual inspection under a stereomicroscope (Leica EZ4, Leica, Wetzlar, Germany) with $30 \times$ magnification were performed to classify the fracture mode into one of three failure modes; 1 ) adhesive failure: denoting fracture in the interface between the ceramic veneer and the zirconia core, 2) cohesive failure: denoting fracture within the ceramic veneer, i.e., chipping, or 3) complete failure: denoting fracture through both the veneer layer and the zirconia core.

\section{Statistical analysis}

The fracture resistance data were tested using a ShapiroWilk test for normality and were further analyzed by one-way analysis of variance (ANOVA) and Tukey's posthoc multiple comparison tests for pairwise comparisons at $p<0.05$, to test the significant differences in fracture resistance between the tested groups. The differences in mode of failure between and within the six groups was revealed using Chi-square test. The inter-examiner agreement was assessed using Kappa statistics. All the statistical analysis tests were performed using SPSS software version 23.0 (SPSS/IBM, Armonk, NY, USA).

\section{RESULTS}

The mean fracture of the six tested groups, measured in $\mathrm{N}$, are listed in Table 1 and presented graphically in Fig. 2. The highest mean fracture resistance was recorded for the (FMC) group, and the lowest fracture resistance was in (FVC) group. The other four groups were ranking between the mentioned groups from highest to the lowest as follow (PVCa), (PVL), (PVCo), and (PVW). One-way ANOVA analysis fracture resistance showed statistically significant differences between the tested experimental groups $(p=0.038)$. Post-hoc Tukey HSD test revealed a significant difference $(p<0.05)$ in fracture resistance of FMC compared to FVC $(p=0.025)$. However, the mean fracture resistance of FMC was not significantly different $(p>0.05)$ compared to PVL, PVCo, and PVW.

None of the tested groups demonstrated adhesive failure mode. All crowns in the FMC, PVL and PVCa groups (100\%) and all but one of the crowns in both PVW and PVCo (93.3\%) showed complete fracture (Fig. $3 a)$ with significant differences $(p=0.025)$ in the fracture mode compared to the FVC where it showed (73.3\%) complete fracture and (26.7\%) cohesive failure (Fig. 3b)

Table 1 Mean fracture resistance (N), standard deviations, significance and Mode of Failure (\%) of the tested experimental groups

\begin{tabular}{|c|c|c|c|c|}
\hline & \multirow{2}{*}{$\begin{array}{c}\text { Fracture resistance } \\
\text { Mean } \pm \text { SD }\end{array}$} & \multicolumn{3}{|c|}{ Mode of failure (\%) } \\
\hline & & Complete & Cohesive & Adhesive \\
\hline (FMC) & $1,140 \pm 198^{\mathrm{a}}$ & 100 & - & - \\
\hline (FVC) & $775 \pm 212^{\mathrm{b}}$ & 73.3 & 26.7 & - \\
\hline (PVL) & $954 \pm 242^{\mathrm{ab}}$ & 100 & - & - \\
\hline (PVCo) & $932 \pm 249^{\mathrm{ab}}$ & 93.3 & 6.7 & - \\
\hline (PVW) & $859 \pm 114^{\mathrm{ab}}$ & 93.3 & 6.7 & - \\
\hline (PVCa) & $975 \pm 312^{\mathrm{ab}}$ & 100 & - & - \\
\hline
\end{tabular}

Note: Values with the same superscript letters were not statistically different at $(p>0.05)$. 
Table 2 In between groups analysis using Chi-square test

\begin{tabular}{|c|c|c|c|}
\hline \multicolumn{4}{|c|}{ Chi-square tests } \\
\hline & Value & $\mathrm{df}$ & $\begin{array}{c}\text { Asymptotic significance } \\
\text { (2-sided })\end{array}$ \\
\hline Pearson chi-square & $12.857^{*}$ & 5 & 0.025 \\
\hline Likelihood ratio & 11.994 & 5 & 0.035 \\
\hline Linear-by-linear association & 7.326 & 1 & 0.007 \\
\hline Number of valid cases & 90 & - & - \\
\hline
\end{tabular}

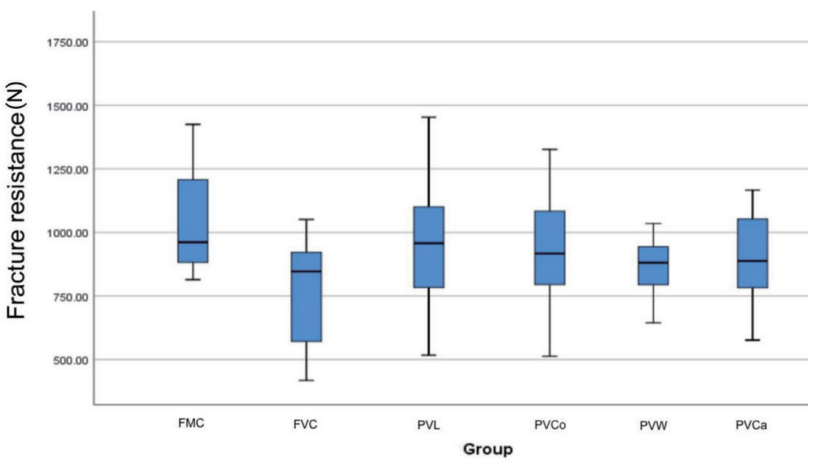

Fig. 2 Box plot representing the median, minimum, maximum and interquartile range of all the groups.

FMC; fully contoured monolithic translucent zirconia crown, FVC; fully veneered translucent zirconia core with $0.5 \mathrm{~mm}$ porcelain veneer, PVL; partially veneered translucent zirconia crown with a $0.5 \mathrm{~mm}$ buccal veneer, PVCo; partially veneered translucent zirconia crown with a $0.5 \mathrm{~mm}$ buccal veneer with $1 \mathrm{~mm}$ buccal collar height, PVW; partially veneered translucent zirconia crown with $0.5 \mathrm{~mm}$ buccal veneer supported by wave design, PVCa; partially veneered translucent zirconia crown with $0.5 \mathrm{~mm}$ buccal veneer supported by occlusal cap design
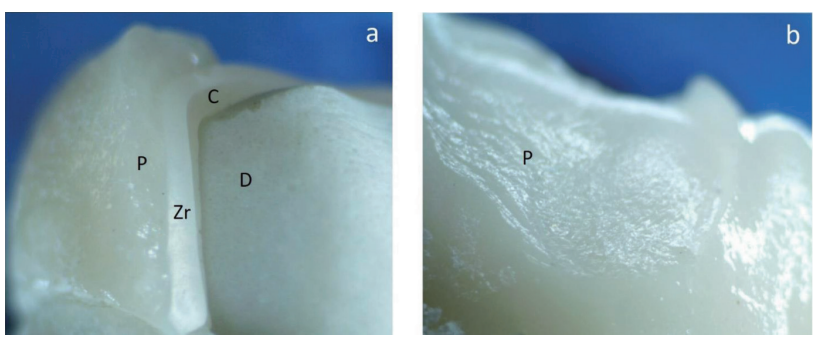

Fig. 3 Representative stereomicroscope images showing a) complete fracture of the crown over the resin die (D), involving porcelain veneer $(\mathrm{P})$, zirconia core $(\mathrm{Zr})$ and cement layer $(\mathrm{C})$, and $\mathrm{b})$ cohesive fracture within the porcelain veneer $(\mathrm{P})$.

using Chi-square statistical test (Table 2). Results of Kappa statistics revealed a very high agreement ( between both examiners for the type of failure.

\section{DISCUSSION}

The one-way ANOVA test showed a significant effect of the crown design among the tested groups $(p=0.038)$, which contraindicates the null hypothesis, and this is why the null hypothesis was rejected.

The results of this study showed that the mean fracture resistance of the fully contoured monolithic translucent zirconia crown FMC exhibited the highest fracture resistance compared to all the other designs. This finding is in agreement with the results of Bakitian et $a l .^{34)}$ who found that the monolithic translucent zirconia crowns had the highest fracture resistance compared to the other tested groups, and the strength of the translucent zirconia can explain this over the glassy lithium disilicate ${ }^{24-26)}$.

The fracture resistance results can be explained according to each suggested crown design. In PVCo design, the cervical collar may have acted as a ferrule, which may have reduced the stresses at the cervical margin, thus increasing the fracture resistance ${ }^{35)}$. For the PVCa, PVW, and PVL designs, most of the occlusal surface is supported by the translucent zirconia. Furthermore, the waves support in the PVW may act to eliminate shear forces from growing on the buccal veneer- zirconia interface. Bakitian et al. tested similar designs to PVCa, PVW, and they reported that the fracture resistance of these groups is approximately close to that with the full monolithic design. Moreover, they reported that the $0.5 \mathrm{~mm}$ partially labial veneer for a full monolithic translucent zirconia crown was inferior to the other tested designs in terms of fracture resistance. The authors contributed their findings to the thickness of the veneered layer, as the thicker the porcelain veneer, the higher probability of flaws within the material, and accordingly, the lower fracture strength. Which will results in, and they suggested keeping the labial veneer thickness to $0.3 \mathrm{~mm}$ in such a design. However, in their study, the fully veneered zirconia crowns were not tested to confirm their conclusion ${ }^{34)}$.

In contrast, the results of the current study showed that mean fracture resistance of PVL was statistically similar to that of FMC. These results can be attributed to the testing setup, where most of the load on the tested samples was mimicking the clinical scenario, in which the palatal cusp of the upper first molar is engaging the 
lingual slope of the buccal cusp of the lower first molar. The buccal cusp was supported by translucent zirconia in all the tested designs of the present study.

In the current study, the lowest mean of the fracture resistance in the tested designs was recorded for FVC, which was reported to exhibit a higher chance of porcelain chipping by several studies ${ }^{10-13)}$ and a lower fracture resistance when compared to the fully monolithic zirconia restorations ${ }^{36,37)}$, in which monolithic crowns displayed a higher resistance to fracture compared to bilayered restoration. Our results showed that the overall mode of failure in the six groups was a cohesive failure (6.7\%) as compared to complete failure (93.3). The Chi-square statistics revealed a significance between the tested groups $(p=0.025)$, which was present between the FVC group and the other tested groups (Table 1).

The present study showed that FMC, PVCa, and PVL showed only a complete failure mode compared to PVW and PVCo where both had presented with (93.3\%) complete failure and $(6.7 \%)$ cohesive failure. Meanwhile, FVC showed $(73.3 \%)$ complete failure and (26.7\%) cohesive failure. These results can be attributed to the chipping tendency of the porcelain veneer, which is the main cause of failure of the bilayered zirconia restoration in both clinical and laboratory studies ${ }^{12}$.

The majority of the mode of failure in the present study were a complete crown fracture, and that can be explained by the impact of the load on the tested designs placed over the translucent zirconia part, and which eliminate the chance of the tensile stresses to build up in the veneer layer. Thus, it resulted in a full load of impact over the zirconia material, where it tested the zirconia structure rather than the bilayered structure.

Some of the fully veneered crown design showed a cohesive failure in the veneered layer in which a thin layer of the porcelain is still attached to the core, and that can be explained by the difference between the veneered porcelain and the zirconia core in terms of the fracture resistance since it is weaker compared to the core and thus making it more prone to fail at lower loads ${ }^{38}$. Other cause of the cohesive failure in the veneer layer can be the high residual stresses in the porcelain layer, and it might be related to the low thermal diffusivity of the zirconia, which can affect the cooling of the veneered layer; that difference in the cooling rate can lead to more residual stresses in the veneered layer ${ }^{39}$.

Bakitian et al. investigated the mode of failure in several translucent crown designs similar to the present study designs FMC, PVW, PVL, and PVCa. They also added $0.3 \mathrm{~mm}$ partially labial veneer for a full monolithic translucent zirconia crown (SM0.3), and they found that both (FMC) and (SM0.3) showed only a complete failure compared to $\mathrm{PVCa}$, the latter showed (95\%) complete failure and (5\%) cohesive failure. However, both PVW and PVL revealed a significant difference of $(70 \%$ and $55 \%$, respectively) of cohesive failure, and (30\% and $45 \%$ respectively) of complete failure ${ }^{34)}$.

Furthermore, the present in vitro fracture resistance testing, using a single compressive unidirectional loading, provides only limited understanding into clinically relevant mechanisms of crown's damage under forces with different directions and cyclic loading and thermal fatigue. It may be anticipated that tensile stresses can induce numerous secondary fractures and generate multiple cracks and different modes of failure ${ }^{40)}$. Thus, further investigation of the proposed crown designs is required under more clinically relevant testing conditions.

\section{CONCLUSIONS}

Within the limitations of the present study, it can be concluded that;

1. The introduced partially veneered translucent zirconia crown designs in the present study showed a comparable fracture resistance to that of the monolithic translucent zirconia crown.

2. The fracture resistance of all the tested crown designs was comparable to that of the full contoured monolithic translucent zirconia crown except for the full veneered design.

3 . The mode of failure of the partially veneered crowns was similar to that of the fully contoured design with minimal chipping of the porcelain veneer. Moreover, FVC showed a higher chance of chipping compared to the other designs.

\section{ACKNOWLEDGMENTS}

This article was part of a thesis submitted in partial fulfillment of the requirements for the degree of Master of Science in Restorative Dentistry from the College of Dentistry, Ajman University, Ajman, UAE.

\section{REFERENCES}

1) Pieger $S$, Salman A, Bidra AS. Clinical outcomes of lithium disilicate single crowns and partial fixed dental prostheses: A systematic review. J Prosthet Dent 2014; 112: 22-30.

2) Pjetursson BE, Sailer I, Zwahlen M, Hämmerle CHF. A systematic review of the survival and complication rates of all-ceramic and metal-ceramic reconstructions after an observation period of at least 3 years. Part I: Single crowns. Clin Oral Implants Res 2007; 18: 73-85.

3) Ambré MJ, Aschan F, von Steyern PV. Fracture strength of yttria-stabilized zirconium-dioxide (Y-TZP) fixed dental prostheses (FDPs) with different abutment core thicknesses and connector dimensions. J Prosthodont 2013; 22: 377-382.

4) Giordano R. Materials for chairside CAD/CAM-produced restorations. J Am Dent Assoc 2006; 137 Suppl: 14S-21S.

5) Peterson IM, Pajares A, Lawn BR, Thompson VP, Rekow ED. Mechanical characterization of dental ceramics by Hertzian contacts. J Dent Res 1998; 77: 589-602.

6) Piconi C, Maccauro G. Zirconia as a ceramic biomaterial. Biomaterials 1999; 20: 1-25.

7) Aboushelib MN, Kleverlaan CJ, Feilzer AJ. Microtensile bond strength of different components of core veneered allceramic restorations. Part II: Zirconia veneering ceramics. Dent Mater 2006; 22: 857-863.

8) Dehoff PH, Anusavice KJ. Viscoelastic finite element stress analysis of the thermal compatibility of dental bilayer ceramic systems. Int J Prosthodont 2009; 22: 56-61.

9) Mosharraf R, Rismanchian M, Savabi O, Ashtiani AH. Influence of surface modification techniques on shear bond 
strength between different zirconia cores and veneering ceramics. J Adv Prosthodont 2011; 3: 221-228.

10) Agustín-Panadero R, Román-Rodríguez JL, Ferreiroa A, Solá-Ruíz MF, Fons-Font A. Zirconia in fixed prosthesis. A literature review. J Clin Exp Dent 2014; 6: 66-73.

11) Al-Amleh B, Lyons K, Swain M. Clinical trials in zirconia: a systematic review. J Oral Rehabil 2010; 37: 641-652.

12) Sailer I, Fehér A, Filser F, Gauckler LJ, Lüthy H, Hämmerle CHF. Five-year clinical results of zirconia frameworks for posterior fixed partial dentures. Int J Prosthodont 2007; 20: 383-388.

13) Tinschert J, Schulze KA, Natt G, Latzke P, Heussen N, Spiekermann H. Clinical behavior of zirconia-based fixed partial dentures made of DC-Zirkon: 3-year results. Int J Prosthodont 2008; 21: 217-222.

14) Anusavice KJ, Dehoff PH, Hojjatie B, Gray A. Influence of tempering and contraction mismatch on crack development in ceramic surfaces. J Dent Res 1989; 68: 1182-1187.

15) Belli R, Monteiro S, Baratieri LN, Katte H, Petschelt A, Lohbauer U. A photoelastic assessment of residual stresses in zirconia-veneer crowns. J Dent Res 2012; 91: 316-320.

16) Swain MV. Unstable cracking (chipping) of veneering porcelain on all-ceramic dental crowns and fixed partial dentures. Acta Biomater 2009; 5: 1668-1677.

17) Taskonak B, Borges GA, Mecholsky JJ, Anusavice KJ, Moore BK, Yan J. The effects of viscoelastic parameters on residual stress development in a zirconia/glass bilayer dental ceramic. Dent Mater 2008; 24: 1149-1155.

18) Albashaireh ZSM, Ghazal M, Kern M. Two-body wear of different ceramic materials opposed to zirconia ceramic. J Prosthet Dent 2010; 104: 105-113.

19) Griffin JD Jr. Combining monolithic zirconia crowns, digital impressioning, and regenerative cement for a predictable restorative alternative to PFM. Compend Contin Educ Dent 2013; 34: 212-222

20) Kontonasaki E, Rigos AE, Ilia C, Istantsos T. Monolithic zirconia: An update to current knowledge. Optical properties, wear, and clinical performance. Dent J 2019; 7: 90-113.

21) Tong H, Tanaka CB, Kaizer MR, Zhang Y. Characterization of three commercial Y-TZP ceramics produced for their hightranslucency, high-strength and high-surface area. Ceram Int 2016; 42: 1077-1085.

22) Harianawala HH, Kheur MG, Apte SK, Kale BB, Sethi TS, Kheur SM. Comparative analysis of transmittance for different types of commercially available zirconia and lithium disilicate materials. J Adv Prosthodont 2014; 6: 456-461.

23) Thompson JY, Stoner BR, Piascik JR, Smith R. Adhesion/ cementation to zirconia and other non-silicate ceramics: Where are we now? Dent Mater 2011; 27: 71-82.

24) Chen YM, Smales RJ, Yip KHK, Sung WJ. Translucency and biaxial flexural strength of four ceramic core materials. Dent Mater 2008; 24: 1506-1511.

25) Fischer J, Stawarczyk B, Hämmerle CHF. Flexural strength of veneering ceramics for zirconia. J Dent 2008; 36: 316-321.

26) Kwon SJ, Lawson NC, McLaren EE, Nejat AH, Burgess JO. Comparison of the mechanical properties of translucent zirconia and lithium disilicate. J Prosthet Dent 2018; 120: 132-137.

27) Beuer F, Stimmelmayr M, Gueth JF, Edelhoff D, Naumann M. In vitro performance of full-contour zirconia single crowns. Dent Mater 2012; 28: 449-456.

28) Nakamura K, Harada A, Inagaki R, Kanno T, Niwano $Y$, Milleding $\mathrm{P}$, et al. Fracture resistance of monolithic zirconia molar crowns with reduced thickness. Acta Odontol Scand 2015; 73: 602-608.

29) Attia A, Kern M. Influence of cyclic loading and luting agents on the fracture load of two all-ceramic crown systems. J Prosthet Dent 2004; 92: 551-556.

30) Fathy SM, El-Fallal AA, El-Negoly SA, El Bedawy AB. Translucency of monolithic and core zirconia after hydrothermal aging. Acta Biomater Odontol Scand 2015; 1: 86-92.

31) Zhang F, Vanmeensel K, Batuk M, Hadermann J, Inokoshi M, Van Meerbeek B, et al. Highly-translucent, strong and aging-resistant 3Y-TZP ceramics for dental restoration by grain boundary segregation. Acta Biomater 2015; 16: 215222.

32) O'Brien WJ, Boenke KM, Groh CL. Coverage errors of two shade guides. Int J Prosthodont 1991; 4: 45-50.

33) Yu B, Ahn JS, Lee YK. Measurement of translucency of tooth enamel and dentin. Acta Odontol Scand 2009; 67: 57-64.

34) Bakitian F, Seweryniak P, Papia E, Larsson C, Von Steyern PV. Effect of different semimonolithic designs on fracture resistance and fracture mode of translucent and hightranslucent zirconia crowns. Clin Cosmet Investig Dent 2018; 10: $51-60$.

35) Øilo M, Schriwer C, Flinn B, Gjerdet NR. Monolithic zirconia crowns -wall thickness, surface treatment and load at fracture. Biomater Investig Dent 2019; 6: 13-22.

36) Lameira DP, Silva WABE, Silva FAE, De Souza GM. Fracture strength of aged monolithic and bilayer zirconiabased crowns. Biomed Res Int 2015; 2015: 418641.

37) Zhang Y, Lee JJW, Srikanth R, Lawn BR. Edge chipping and flexural resistance of monolithic ceramics. Dent Mater 2013; 29: 1201-1208.

38) Guess PC, Zavanelli RA, Silva NRFA, Bonfante EA, Coelho PG, Thompson VP. Monolithic CAD/CAM lithium disilicate versus veneered Y-TZP crowns: comparison of failure modes and reliability after fatigue. Int J Prosthodont 2010; 23: 434442 .

39) Tholey MJ, Swain MV, Thiel N. Thermal gradients and residual stresses in veneered Y-TZP frameworks. Dent Mater 2011; 27: 1102-1110.

40) Preis V, Behr M, Hahnel S, Handel G, Rosentritt M. In vitro failure and fracture resistance of veneered and full-contour zirconia restorations. J Dent 2012; 40: 921-928. 